\title{
A Multiperiod Supply Chain Network Design Considering Carbon Emissions
}

\author{
Yang Peng, ${ }^{1}$ Jose Humberto Ablanedo-Rosas, ${ }^{2}$ and Peihua Fu ${ }^{1}$ \\ ${ }^{1}$ School of Computer and Information Engineering, Zhejiang Gongshang University, Hangzhou 310018, China \\ ${ }^{2}$ Marketing \& Management Department, College of Business Administration, University of Texas at El Paso, El Paso, TX 79968, USA
}

Correspondence should be addressed to Yang Peng; pengyang@zjgsu.edu.cn

Received 10 January 2016; Revised 7 May 2016; Accepted 19 May 2016

Academic Editor: Muhammad N. Akram

Copyright (C) 2016 Yang Peng et al. This is an open access article distributed under the Creative Commons Attribution License, which permits unrestricted use, distribution, and reproduction in any medium, provided the original work is properly cited.

\begin{abstract}
This paper introduces a mixed integer linear programming formulation for modeling and solving a multiperiod one-stage supply chain distribution network design problem. The model is aimed to minimize two objectives, the total supply chain cost and the greenhouse gas emissions generated mainly by transportation and warehousing operations. The demand forecast is known for the planning horizon and shortage of demand is allowed at a penalty cost. This scenario must satisfy a minimum service level. Two carbon emission regulatory policies are investigated, the tax or carbon credit and the carbon emission cap. Computational experiments are performed to analyze the trade-offs between the total cost of the supply chain, the carbon emission quantity, and both carbon emission regulatory policies. Results demonstrate that for a certain range the carbon credit price incentivizes the reduction of carbon emissions to the environment. On the other hand, modifying the carbon emission cap inside a certain range could lead to significant reductions of carbon emission while not significantly compromising the total cost of the supply chain.
\end{abstract}

\section{Introduction}

Today global supply chains are expected to meet requirements beyond economic performance [1-3]. Corporate stakeholders increasingly encourage organizations to develop a sustainable operational model across the supply chain [4]. The concept of a sustainable business model has become a competitive priority for global companies wanting to increase market share. It is commonly accepted that sustainable development has three dimensions: social, economic, and environmental [1].

Large scale emissions of greenhouse gasses (GHG) are a top current environmental concern. GHG emissions represent serious and irreversible harm to the environment. As a result, GHG emissions have attracted the attention of governments, practitioners, and research institutions. Governments are under growing societal pressure to enact legislation to curb the amount of GHG emissions. Consumers, stakeholders, and legislation have pushed supply chains to redesign their logistics networks in order to mitigate negative environmental impacts [5]. Transportation, which is the most visible aspect of supply chains, accounts for carbon dioxide
$\left(\mathrm{CO}_{2}\right)$ emissions of about $15 \%$ of total global $\mathrm{CO}_{2}$ emissions [6].

Globalization has led to the development of large trade streams of goods all throughout the world, which have created large environmental problems [6]. The supply chain processes of moving and storing products and other materials (e.g., supplies, raw materials, and component parts) require significant amounts of energy and result in the creation of large amounts of emissions from transportation, equipment, and storage warehouses. This is an important macrosocietal issue for supply chain practitioners who should understand the impact of carbon emissions and define appropriate carbon usage strategies in order to improve operations and reduce carbon emissions.

Environmental or green supply chain management can be defined as integrating environmental aspects into supply chain network design, covering both forward and reverse product flows across the supply chain. It comprehends the overall operations from product design to product end-of-life management. Some products are environmentally friendlier than others. In fact, there are three product characteristics considered to judge how environmentally friendly products 
are: the way products have been produced (their carbon footprint), the way products have been transported and waiting for use (inventories), and the products' value recovered after their use (reverse logistics) [6]. Facilities also contribute to environmental issues. In recent years, the terms green facility and green buildings have gained much popularity. Important related aspects are internal transport and emissions, energy use of facilities, and congestion around facilities, among others [6]. This paper introduces an optimization model which considers GHG emissions generated by product transport and product storage at both factories and sales points.

Green supply chain management has not been adopted not only because of the economic motivation but also due to regulatory pressure [7]. Different regulatory mechanisms have been defined to tackle GHG emissions. Supply chains foresee the development of carbon-control mechanisms such as carbon tax and cap-and-trade systems. Excessive carbon emissions are viewed as a symptom of corporate misgovernance and a source of risk and uncertainty [2,3]. Benjaafar et al. [8] illustrated how carbon emissions are integrated into procurement, production, and inventory management decisions. They analyzed different emission regulations including strict emission caps, taxes on emissions, cap-and-offset, and cap-and-trade. They concluded that supply chain collaboration and operational/structural adjustments are inexpensive critical drivers for reducing the supply chain carbon footprint. This paper investigates the effect of two GHG emission regulations (carbon emission tax and carbon emission cap) and network (operational/structural) design simultaneously.

There is a growing research stream aimed at the integration of strategic and tactical/operational decisions in supply chain distribution network design [9]. Still, green/ environmental issues in supply chain network design (SCND) are incipient [8]. A well-structured SCND is a critical strategy that enables firms to be competitive in today's global markets. Furthermore, SCND plays an important role in the overall environmental and economic performance of the supply chain. In general, SCND deals with determining the locations, numbers, and capacities of network facilities as well as the aggregate material flow between them [10]. SCND models have traditionally focused on minimizing fixed and operating costs without taking carbon emissions into account; few researchers have investigated carbon emissions in the SCND problem. The motivation and goal of this paper are to study a novel green supply chain network design problem which integrates carbon emission decisions.

This paper considers a multiperiod supply chain network setting which frequently arises in operational activities at specific oriented manufacturing industries. This case was observed at a manufacturer who has several production facilities and several points of sale. The manufacturers make a decision about how to satisfy demand, at the minimum total cost (transportation, warehousing, and emissions), with a minimum customer service level, using rented transportation units, delivering by direct shipping to one point of sale at a time (no routing decision are made), and during a multiperiod planning horizon defined by a master production schedule.
The rest of the paper is organized as follows. Section 2 presents a literature review about the green supply chain distribution network design problem. Section 3 describes the problem definition and introduces the proposed mathematical programming model. Section 4 discusses the experimental case and computational results. Finally, Section 5 provides conclusions and remarks for future research.

\section{Literature Review}

This paper tackles a novel problem that arises from the combination of supply chain network design with the incipient developments about carbon emissions in the supply chain. Hence, this section is divided into three subsections. First, we review a few recent research articles about the supply chain network design problem. Second, we briefly examine the literature on sustainable supply chain related to carbon emissions. Lastly, based on the literature review, we state the purpose and contribution of this research article.

2.1. Supply Chain Network Design Problem. SCND determines the structure of a supply chain network which affects its costs and performance [11]. It is common that SCND includes a variety of strategic decisions (long term decisions such as number, size, and location of facilities), tactical decisions (medium term decisions such as distribution, transportation, and inventory management policies), and operational decisions (short term decisions such as fulfilling customers demand). The SCND problem covers a set of comprehensive problems which range from simple single product type to complex multiproduct and from linear deterministic models to complex nonlinear stochastic ones, among other classifications. The SCND problem has been extensively studied by practitioners and researchers. Nagy and Salhi [12] presented a survey of the location-routing problem. Melo et al. [9] performed a literature review of facility location models in the context of supply chain management. Klibi et al. [10] presented a critical review of the SCND problem under uncertainty. Farahani et al. [11] reviewed the SCND literature highlighting the effects of a competitive environment in SCND. We now perform a brief literature review of recent SCND research articles focused on the following issues: multiple decision variables and objectives, risk and social responsibility, determinist and stochastic approaches, and routing decisions and reverse logistics models.

Multiple decision variables and objectives are inherent characteristics of the SCND problem. Amiri [13] addressed the distribution network design problem in the supply chain determining the best strategy for distributing the product from the plants to the warehouses and from the warehouses to the customers. The decision variables were the numbers, locations, and capacities of both warehouses and plants. Azaron et al. [14] considered demands, supplies, processing, transportation, shortage, and capacity expansion costs as the uncertain parameters. Their multiobjective model included (i) the minimization of current investment costs and the future processing, transportation, shortage, and capacity 
expansion costs, (ii) the minimization of the variance of the total cost, and (iii) the minimization of the financial risk.

Recently, the SCND problem has been extended in different dimensions such as risk $[15,16]$ and social responsibility [17]. Franca et al. [15] developed a method for assessing the systemic supply chain risk of poor quality. They evaluated trade-offs between profit and quality. Speier et al. [16] investigated supply chain design strategies that can be implemented to mitigate risk. The approach was developed by integrating three theoretical perspectives-normal accident theory, high reliability theory, and situational crime prevention. Pishvaee et al. [17] addressed the problem of socially responsible supply chain network design under uncertain conditions. The model controls the opening of plants and distribution centers and manages the quantity of product shipped between plants and distribution centers and between distribution centers and customers. The first component of the objective function minimizes the total cost including fixed opening costs, variable production costs, and transportation costs. The second component calculates social responsibility including maximization of job opportunities, minimization of total produced wastes, lost days caused from work's damages, and number of potentially hazardous products.

Deterministic and stochastic approaches have been extensively used to solve the SCND problem as well. Sadjady and Davoudpour [18] researched a two-echelon SCND problem in a deterministic, single-period, multicommodity context. The problem involves locating and sizing manufacturing plants and distribution warehouses, selecting transportation modes, assigning the retailers' demands to the warehouses, and assigning the warehouses to the plants. The problem intends to minimize total costs of the network including transportation, lead time, and inventory holding costs for products, as well as opening and operating costs for facilities. Cardona-Valdés et al. [19] studied a two-echelon production distribution network design problem with multiple manufacturing plants, distribution centers, and customers. They incorporated the demand uncertainty of customers within the distribution center location and transportation mode allocation decisions. The stochastic model was intended to minimize total cost and total service time. Baghalian et al. [20] developed a mathematical formulation for designing a multiproduct supply chain considering capacitated production facilities, distribution centers, and retailers in markets under uncertainty. They investigated the impact of strategic facility location decisions on operational inventory and shipment decisions. They analyzed a real case created in the agrofood industry.

Other special dimensions in SCND are routing decisions [21], reverse logistics [22], supply chain flexibility [23], and agile manufacturing scenarios [24]. An inventorylocation model considering routing decisions was presented by Ahmadi Javid and Azad [21]. They studied a model to simultaneously optimize location, allocation, capacity, inventory, and routing decisions in a stochastic supply chain network. Cardoso et al. [22] developed a model for designing a supply chain with reverse flows while simultaneously considering demand uncertainty, production, distribution, and reverse logistics activities. The objective was to maximize the expected net present value. They solved a European supply chain case to illustrate the applicability of the model. Esmaeilikia et al. [23] studied a tactical supply chain planning model with multiple flexibility options. Supply chain flexibility is recognized to manage uncertainty which may arise from demand and supply interruptions and lead time variability. They found that supply chain flexibility does not come free and that flexibility-related decisions in one process must be made with respect to the available flexibility options in other processes. Pan and Nagi [24] analyzed a supply chain network design problem in an agile manufacturing scenario with multiple echelons and multiple periods, where multiple customers have heavy demands. Decision variables included selection of one or more companies in each echelon, production quantity, inventory level, and transportation quantity. The objective function was to minimize the total cost including fixed alliance costs between companies, production, holding, and transportation costs.

2.2. Sustainable Supply Chain. There is a large amount of literature on sustainable supply chains (SSC). We present a representative sample of papers aimed at investigating benefits of SSC, emissions modeling, environmental taxes, emission trade systems, and life cycle assessment. Supply chain sustainability has three dimensions: social, economic, and environmental [1]. Perhaps the most researched dimensions are the economic and environmental ones. Neto et al. [5] developed a multiobjective framework for the design of sustainable supply chain networks. The model balances profits and environmental impacts. The industrial sector has been under pressure to significantly decrease the negative environmental impact in the supply chain. The current global and dynamic supply chain environment considers tradeoffs between costs and respective emissions [25]. Seuring and Müller [26] performed an extensive survey in sustainable supply chain management. They concluded that SSC research is still dominated by green/environmental issues; social aspects and the integration of the three dimensions of sustainability are still rare. Other sustainable supply chain related surveys have been completed. Hassini et al. [27] performed a literature review of sustainable supply chains with a focus on metrics. Dekker et al. [6] presented a survey of operations research models for green logistics. Sbihi and Eglese [28] define new problems that arise in the field of green logistics. They describe operational research models when the objectives considered are not simply economic but involve wider environmental and social considerations as well. Recently, Brandenburg et al. [29] reviewed almost two decades of research literature focused on formal modeling of SSC issues. They found that most research articles were focused on multiple criteria decision making.

The benefits of sustainable supply chain practices diminish if downstream and upstream partners are not integrated. Global external markets pressure companies to adopt sustainable supply chain practices [30]. Moreover, Klibi et al. [10] argued that supply chain network robustness is a necessary condition to ensure sustainable value creation. Chen and Sheu [31] investigated environmental-regulation 
pricing strategies and concluded that a proper design of these strategies promotes extended product responsibility for green supply chains participating in competitive markets. They found that governments should gradually raise environmental-regulation standards so that manufacturers will gradually improve their product recyclability, and by association extended product responsibility will be encouraged.

Carbon emissions across stages in a supply chain can constitute a significant threat that warrants careful attention in the design phase of supply chains [32]. Krikke [33] researched the carbon footprint of a copy machine in a closed-loop supply chain. Lessons from this research are threefold. First, additional transport of returned items creates an additional footprint, but the alternative of local repair and scrap contributes much more to carbon footprint reduction than transport optimization. Second, the overall footprint decreases in regional networks but only when the full set of closed-loop recovery options is feasible. Third, having closed-loop recycling in the set of recovery options strongly improves the robustness of closed-loop supply chains to quality loss of returns over time. Another real case was analyzed by Ageron et al. [30]. They developed a theoretical sustainable supply chain framework based on perceptions and practices of selected French companies. They analyzed firms in the following sectors: manufacturing (75\%), power generation and distribution (6\%), medical and pharmaceutical sectors $(6 \%)$, sales and distribution (7\%), and logistics service providers $(6 \%)$. Their results showed that the two main reasons for adopting sustainable supply chain practices are top management vision and government regulatory requirements. Furthermore, they confirmed that the two main barriers for sustainable SCND are indeed financial costs and green investments.

Models quantifying the amount of gas emissions have been utilized in SCND. Wang et al. [34] studied the environmental investment decisions in the design phase and proposed a multiobjective optimization model that captures the trade-off between the total cost and the environmental influence. The decision variables were the flow of product between nodes, the environment protection level in each facility, and a binary variable for controlling open facilities. They considered two objective functions. The first objective measures the total cost (fixed setup cost, environmental protection investment, transportation cost, and handling cost). The second objective measures the total $\mathrm{CO}_{2}$ emission in all the supply chain (emissions in facilities and supplier and transport emissions). They observed that improving the capacity of the network and increasing the supply to the facilities can decrease the $\mathrm{CO}_{2}$ emissions and the total cost of the whole network. Similarly, Elhedhli and Merrick [35] researched a SCND problem considering $\mathrm{CO}_{2}$ emission alongside fixed and variable location and production costs. They modelled with a concave function the relationship between $\mathrm{CO}_{2}$ emissions and vehicle weight. Their results indicated that considering emission costs can change the optimal configuration of the supply chain. Therefore, emission costs should be considered when designing sustainable supply chains. The variables in their model were the number of units shipped from plants to warehouses and two location variables managing the assignment of customers to distribution centers and distribution centers openings. The objective function included emission costs, the fixed cost of opening distribution centers, and the handling and transportation cost. Other gas emissions were investigated by Jamshidi et al. [36]. They proposed an optimization model considering transportation, holding and backorder costs, and the amount of carbon monoxide $(\mathrm{CO})$, nitrogen oxide $\left(\mathrm{NO}_{2}\right)$, and volatile organic particles produced by facilities and transportation. The model has binary and continuous variables, the former manage the openings of facilities and the latter manage the quantities of products/raw material shipped/transported between facilities. The objective function is multiobjective including $\mathrm{NO}_{2}$ gas, $\mathrm{CO}$ gas, volatile organic particles, fixed cost of opened facilities, variable cost at facilities, transportation cost between facilities, raw material cost, backorder cost, and inventory holding cost.

The environmental taxes, fees, or charges represent prices for the discharge of pollutants into the environment and are based on the quantity and/or quality of the pollutant. These fees are essentially different from most existing taxes, because they are not designed to raise revenue but to reduce emissions. Ramudhin et al. [37] developed a mathematical formulation to decide on the best configuration strategy that will comply with regulations while yielding more profit. The supply chain could qualify for carbon credits or could require the purchase of carbon credits on the carbon market place. Decision variables correspond to number of units produced, number of units shipped, number of shipments, opening of plants and distribution centers, product assignments, and transportation modes. The cost component of the objective function includes fixed costs, variable costs, and cost/profit of emissions. The second component minimizes the quantity of carbon dioxide produced by transportation and manufacturing activities.

The cap-and-trade system has been studied by several authors. Du et al. [38] and Du et al. [39] investigated the impact of the cap-and-trade mechanism in an emissiondependent supply chain with the emission permit supplier and the emission-dependent firm. They considered two major sources of emission permits, caps imposed by the government and permits purchased via emission trading. They proved that the manufacturer's profit increases with the emission cap, while the permit supplier's decreases. Dong et al. [40] studied the sustainability investment on sustainable product with emission regulation consideration for decentralized and centralized supply chains. They concluded that cap-and-trade regulation is an effective way to reduce the carbon emission.

The survey performed by Seuring [41] showed life cycle assessment (LCA) based approaches as dominant strategies for assessing the impact of environmental models. Abdallah et al. [25] developed a mixed integer program for the carbonsensitive supply chain with green procurement. The program models a three-stage multicommodity facility location problem with carbon trading and green procurement. The costs considered are the unit cost of raw material, the facility opening cost, the distribution cost, and the carbon emission 
costs. The carbon emission costs come from four sources: (1) raw material, where the manufacturer is held responsible for it (green procurement); (2) transportation (distance and weight) of raw material (green procurement); (3) facilities (plants and distribution centers), where the amount of emission is proportional to the facility's area; and (4) transportation (distance and weight) of the product. They analyzed a case with three different configurations: (1) no carbon cost, (2) a fixed carbon cost, and (3) minimum carbon emissions scenario (greenest model). They used LCA to compare the environmental impacts of the three scenarios and concluded that, for the analyzed case, the embedded emissions in the procured materials dominated the total emissions. The decision variables were location of distribution centers, units of product shipped from distribution centers to retailers, location of plants, units of product shipped from plants to distribution centers, number of units of raw material shipped from suppliers to plants, location of suppliers, and amount of carbon dioxide that was emitted. Chaabane et al. [2] developed a mixed integer linear programming framework for sustainable SCND that considers LCA principles. The model considers solid and liquid wastes as well as gas emissions due to various production processes and transportation systems. They analyzed the trade-offs between economic and environmental objectives in the aluminum industry. Their conclusion was the fact that efficient carbon management strategies help to achieve sustainability objectives in a costeffective manner. The decision variables were classified as follows: sites location (plants and recycling centers), units produced, transportation, and carbon management. The objective function had two components: economic and environmental. The economic component included location, supply, production, distribution, reverse logistics, transportation, and LCA based costs and carbon credit component. The environmental component considered the minimization of GHG to ensure environmental sustainability. They concluded that the integration of LCA principles at the supply chain design phase maximizes the long term sustainability.

2.3. Purpose and Contribution of This Paper. The approach presented in this paper is similar to the one presented by Elhedhli and Merrick [35]. They analyzed a supply chain network design problem aimed at minimizing the costs to set up a facility, the production costs, the transportation cost to deliver goods, and the cost of emissions. However, our approach differs in the following aspects:

(1) The literature review shows a common practice for developing multiobjective mathematical formulations. Contrary to Elhedhli and Merrick [35], we introduce a biobjective optimization model, where the economic profitability and the carbon emission issue are simultaneously considered. Furthermore, two different carbon emission policies are analyzed.

(2) We extend on Elhedhli and Merrick [35] by introducing a multiperiod model which arises in several real situations, where the master production schedule is an input for the decision making process. Therefore, holding cost, setup cost, loss of sales cost, transportation cost, and carbon emission cost are considered along a planning horizon.

(3) Additionally, the model considers direct shipping, a desired customer service level, and transportation costs estimated as a linear function of the number vehicles and distance traveled. When using a single mode of transportation and full truckloads, the transportation cost function could be modelled as a linear function [35]. In this case, the manufacturer can select a truck among a wide variety of available load capacity vehicles. Hence, the associated cost could be approximated by a linear function of the corresponding truck capacity.

\section{Problem Statement and Proposed Model}

3.1. Problem Description and Assumptions. We consider a one-stage supply chain network $G=(N, A)$, where $N$ is the set of nodes and $A$ is the set of $\operatorname{arcs} ; N$ is composed by the set of factories $F$ and the set of sales points $S$; that is, $N=F \cup S$. Each factory node is connected to each sales point node by an arc with an associated cost. The parameters of the problem include the demand forecast at each sales point and for each period in the planning horizon, capacity at each factory, holding cost, setup cost, lost sales cost, vehicle capacity, customer service level, vehicle transportation cost, and cost of carbon credits. In order to determine the product quantities shipped from the factories to the sales points, an aggregate forecast for a planning horizon is estimated. Given the demand forecast, it is feasible to generate a proper master production/distribution schedule for the planning horizon. Moreover, this multiperiod scheduling problem also considers the impact of GHG emissions during the planning horizon.

In the described supply chain network design problem, the decision variables at each period of the planning horizon are described as follows: the procurement from upstream (factories) to the downstream nodes (points of sales) and the transportation cost from the factories to the point of sales which is estimated by the number of vehicles used from the upstream to the downstream nodes. Both factories and points of sale are able to store some product incurring in inventory holding costs. The model allows the decision to activate or not production at a specific factory at a specific time period while incurring in a setup cost. Sales points are allowed to have unsatisfied demand; the stock-out cost is estimated by a penalized loss of sales based on the desired customer service level. The objective of the mathematical formulation is to optimize and balance the carbon emissions and the economic cost.

The supply chain network design model takes into account the carbon emissions generated by the decision making variables associated with factory allocation and product quantity transported. Hence, the model considers carbon emissions from warehousing and transportation operations, which is similar to Konur and Schaefer [42]. The approach for determining the carbon emission factors is like the 
method presented by Martí et al. [43] and Hammami et al. [44]. Carbon emissions from inventory are proportional to inventory levels, and carbon emissions from transportation are proportional to load weight and distance.

Other assumptions in the proposed mixed integer linear programming model are stated as follows:

(1) The forecasted demand at each sales point can be satisfied by more than one factory, and the cumulative capacity of the factories is greater than the total demand of all sales points in the overall planning horizon.

(2) In practice, transportation activities are done either with trucks or with other means of transport; many corporations often rent trucks instead of own vehicles to undertake the transportation. Accordingly, the total transportation cost is a function of the number of vehicles used to undertake transportation activities.

(3) The transportation process from the upstream to the downstream does not involve routing decisions. The shipping load is relatively large for assuming direct distribution.
3.2. Mathematical Models. Parameters in the model are defined in Abbreviations.

The total carbon emissions associated with warehousing operations are modelled as follows.

$\mathrm{EI}_{i}^{t}$ is the amount of carbon emissions per unit of inventory held in facility $i$ over time period $t$. We assume the emission level is uniform in every period and $\mathrm{EI}_{i}^{t}$ can be replaced by $\beta$.

The total carbon emissions associated with transport operations are modelled as follows:

$$
\mathrm{ET}_{i j}^{t}=\alpha q_{i j}^{t} d_{i j}
$$

where $\mathrm{ET}_{i j}^{t}$ represents the carbon emission amount produced by transportation operations from factory $i$ to sales point $j$ over time period $t$.

The total economic cost of the supply chain network, which includes fixed and variable costs of transportation and storage operations, is formulated as the objective function $F_{1}$ and defined by the following:

$$
\min F_{1}=\sum_{t=1}^{T}\left(\sum_{i=1}^{F}\left(h_{i}^{t} \sigma_{i}^{t}+\theta_{i}^{t} y_{i}^{t}\right)+\sum_{j=1}^{S}\left(h_{j}^{t} \sigma_{j}^{t}+L_{j} \delta_{j}^{t}\right)+\sum_{i=1}^{F} \sum_{j=1}^{S} N_{i j}^{t} k_{i j}\right) .
$$

The second objective function $F_{2}$ aimed at minimizing the total GHG emission quantity is given by the following:

$$
\begin{array}{ll}
\min & F_{2} \\
& =\alpha \sum_{t=1}^{T} \sum_{i=1}^{F} \sum_{j=1}^{S} q_{i j}^{t} k_{i j}+\beta\left(\sum_{t=1}^{T} \sum_{i=1}^{F} \sigma_{i}^{t}+\sum_{t=1}^{T} \sum_{j=1}^{S} \sigma_{j}^{t}\right) .
\end{array}
$$

The mixed integer linear mathematical programming formulation of the green SCDN problem is completed with the following sets of constraint:

$$
\begin{aligned}
& \sigma_{j}^{t-1}+\sum_{i=1}^{F} q_{i j}^{t}+\delta_{j}^{t}-d_{j}^{t}=\sigma_{j}^{t} \quad \forall j, \forall t, \\
& \sum_{j=1}^{S} q_{i j}^{t}+\sigma_{i}^{t}=C_{i} y_{i}^{t}+\sigma_{i}^{t-1} \quad \forall i, \forall t, \\
& \delta_{j}^{t} \leq(1-\mathrm{CSL}) d_{j}^{t}, \quad \forall j, \quad \forall t, \\
& q_{i j}^{t} \leq N_{i j}^{t} \varphi \quad \forall i, j, t, \\
& q_{i j}^{t}, N_{i j}^{t}, \sigma_{i}^{t}, \sigma_{j}^{t}, \delta_{j}^{t} \geq 0, \\
& y_{i}^{t} \in\{0,1\}, \quad \forall i, t .
\end{aligned}
$$

The set of inequalities (4) represents the stock balance between time period $t$ and time period $t-1$. Those inequalities (5) assure the flow balance at the factories. The shortage of demand restricted by customer service level is managed by the set of constraints (6). The set of inequalities (7) controls that the transported product quantity from the factory to the sales point does not exceed the feasible capacity of the vehicles utilized. The set of constraints (8) assures that the corresponding variables are positive, and set of constraints (9) identifies the binary variables.

\section{Computational Experiments}

There exists a variety of commercially available optimization software for solving mixed integer linear programing problems. We used MATLAB and CPLEX to solve the proposed mathematical programming model.

The purpose of multiobjective mathematical programming models is to find efficient solutions considering all the objective functions at the same time. Hence, an efficient solution has the property that it is infeasible to improve any objective function without adversely affecting at least one other objective function value. The finite number of efficient solutions generates what is called trade-off surface or Pareto front.

Two classical methods for handling multiobjective optimization problems are the weighted sum method and the $\varepsilon$ constraint method. These methods perform a transformation of the original problem into a monoobjective optimization problem which could be solved using commercial software such as CPLEX. 
TABLE 1: Information regarding the sales points.

\begin{tabular}{|c|c|c|c|c|c|c|}
\hline Demand (units) & Hangzhou & Ningbo & Hefei & Shanghai & Zhuzhou & Nanchang \\
\hline$D_{t=1}$ & 50 & 35 & 45 & 60 & 77 & 65 \\
\hline$D_{t=2}$ & 40 & 56 & 45 & 57 & 63 & 39 \\
\hline$D_{t=3}$ & 55 & 47 & 30 & 65 & 28 & 52 \\
\hline Lost sale cost/unit & 8 & 10 & 12 & 11 & 9 & 10 \\
\hline Storage cost/unit & 20 & 18 & 30 & 50 & 42 & 35 \\
\hline
\end{tabular}

The weighted sum method is the simplest approach and probably the most widely used classical method. This method scales the set of objectives into a single objective by multiplying each objective with a user supplied weight. The weighted sum method is simple and easy to use. For convex problems it guarantees finding solutions on the entire Pareto optimal set. However, the method presents some disadvantages. In the case of mixed optimization problems (min.-max.), the objectives need to be converted into one type. Uniformly distributed sets of weight do not guarantee a uniformly distributed set of Pareto optimal solutions. Similarly, two different sets of weight vectors do not necessarily lead to two different Pareto optimal solutions. There may exist multiple minimum solutions for a specific weight vector which represent different solutions in the Pareto optimal front which results in misspent search effort.

The $\varepsilon$-constraint method overcomes some of the convexity problems of the weighted sum method. This method involves minimizing a primary objective and expressing the other objectives in the form of inequality constraints. The method can be used for nonconvex multiobjective optimization problems. Different Pareto optimal solutions can be found using different $\varepsilon$ values. This method presents some disadvantages as well. The solution to the optimization problem largely depends on the selection of $\varepsilon$ vector. As the number of objectives increase, the selection of $\varepsilon$ becomes more important.

This paper adopts both the weighted sum and the $\mathcal{\varepsilon}$ constraint methods. The methods are used to model the framework of two practical emission control policies. The weighted sum method matches the procurement of carbon credits scenario, while the $\varepsilon$-constraint method corresponds to the carbon emission cap environmental policy.

4.1. Simulation Experiment. Based on the case of a household electrical appliance manufacturing industry in China, we develop a set of simulation instances to test the applicability of the model, gain insight about two different environmental regulations, and infer managerial recommendations for decision makers. This Chinese household electrical appliance manufacturer has four factories in four cities (Wuxi, Guangzhou, Chongqing, and Zhengzhou) and six sales points in another six cities (Hangzhou, Ningbo, Hefei, Shanghai, Zhuzhou, and Nanchang). We consider a planning horizon of three periods of time: the information about demand, the cost of lost sales, and the storage cost are given in Table 1 . The objective is to deliver the product to the sales points at the minimum cost and with a minimum customer service level
TABLE 2: Information regarding the factories.

\begin{tabular}{lcccc}
\hline & Wuxi & Guangzhou & Chongqing & Zhengzhou \\
\hline Capacities & 300 & 250 & 220 & 350 \\
Setup cost & 3000 & 3200 & 2000 & 3500 \\
Holding cost/unit & 6 & 5 & 7 & 4 \\
\hline
\end{tabular}

(CSL) of 95\%. Table 2 provides the capacity at each factory and its corresponding setup and holding cost. Delivery is performed by one type of vehicle with capacity of seventy units; the corresponding vehicle transportation costs from each factory to each point of sale are given in Table 3.

Table 4 shows the carbon emission factors for inventory and transportation. Note that GHG emission factors vary according to factors such as the mode and technology used. A reliable reference for finding GHG emission factors is the Intergovernmental Panel on Climate Change [45] and the environmental protection agency [46].

\subsection{Computational Results and Discussions}

4.2.1. Distribution Network without Considering the Carbon Emission. In this section, we analyze the mixed integer optimization problem without considering the carbon emission component (see (3)). This model corresponds to objective function $F_{1}$ given by (2) and the set of constraints given by (4) to (9). The solution of this problem corresponds to the most economic plan to deliver the product during the defined planning horizon.

The effect of varying the vehicle capacity in the total cost is investigated. One type of vehicle with capacity $\varphi$ provides the transportation service between factories and sales points. It is expected that the number of vehicles, which is linked to GHG emissions, will change as the vehicle capacity changes. The vehicle capacity change implies a transportation cost change. We use a simple proportion to linearly estimate the new transportation cost. For example, if the vehicle capacity was 70 units at a cost of $\$ 1000$, then when the vehicle capacity was changed to 140 units the associated transportation was changed to $\$ 2000$. The problem was solved for different vehicle capacities and the results are shown in Figure 1.

Figure 1 illustrates the relationship between vehicle capacity (units) and the total supply chain cost. The results show that the total cost increases as the vehicle capacity increases. This result may somewhat disagree with common sense, but the reason is that each vehicle serves just one factory and one sales point at a time. Any capacity increase may bring a larger 
TABLE 3: Vehicle transportation cost from each factory to each sales point.

\begin{tabular}{|c|c|c|c|c|c|c|}
\hline & Hangzhou & Ningbo & Hefei & Shanghai & Zhuzhou & Nanchang \\
\hline Wuxi & 200 & 310 & 250 & 180 & 170 & 330 \\
\hline Guangzhou & 1500 & 1300 & 2200 & 3000 & 2100 & 1700 \\
\hline Chongqing & 2400 & 600 & 1200 & 800 & 1800 & 1100 \\
\hline Zhengzhou & 900 & 600 & 1050 & 1500 & 950 & 1600 \\
\hline
\end{tabular}

empty loading rate, and the total cost will increase. If a vehicle could serve several factories and/or sales points in the same trip, then the result would be greatly different.

4.2.2. Considering the Carbon Emission under Carbon Tax or Procurement of Carbon Credit. A carbon tax can take a variety of forms; the simplest one is a linear financial penalty in the quantity of carbon emitted. The biobjective optimization problem, defined by (2) and (3), can be transformed into a single objective optimization problem. We add the total economic cost of the supply chain network $\left(F_{1}\right)$ and the total GHG emission quantity $\left(F_{2}\right)$ penalized by $\Omega$. This approach is given by (10). The new objective function $F$ defined by (10) corresponds to the weighted sum method, briefly described at the beginning of Section 4, and broadly used to solve multiobjective optimization problems:

$$
\begin{aligned}
\min \quad F & =F_{1}+\Omega F_{2} \\
& =\sum_{t=1}^{T}\left(\sum_{i=1}^{F}\left(h_{i}^{t} \sigma_{i}^{t}+\theta_{i}^{t} y_{i}^{t}\right)+\sum_{j=1}^{S}\left(h_{j}^{t} \sigma_{j}^{t}+L_{j} \delta_{j}^{t}\right)+\sum_{i=1}^{F} \sum_{j=1}^{S} N_{i j}^{t} k_{i j}\right)+\Omega\left(\alpha \sum_{t=1}^{T} \sum_{i=1}^{F} \sum_{j=1}^{S} q_{i j}^{t}+\beta\left(\sum_{t=1}^{T} \sum_{i=1}^{F} \sigma_{i}^{t}+\sum_{t=1}^{T} \sum_{j=1}^{S} \sigma_{j}^{t}\right)\right) .
\end{aligned}
$$

The penalty $\Omega$ denotes the amount of tax paid for each unit of carbon emitted. This penalty can also be regarded as the carbon credit price in the market, so the model can also simulate the scenario when firms purchase the carbon credit at the spot market price. As stated above, the multiobjective optimization problem was reduced to a single objective problem with cost minimization only. The objective function component reflecting GHG emissions to the environment was transformed into the cost of the GHG emissions. Numerous variations of this mathematical formulation are possible; the simple one presented in this paper considers the carbon tax or procurement of carbon credit. There are other alternatives such as incorporating distinct tax schemes or considering nonlinear tax penalties to the emission quantities. It is also possible to incorporate tax schedules in which the penalty changes in discrete steps as a function of the emission quantity, including the case where taxes are not levied if emissions fall below a certain threshold. Depending on the assumption, some of these variations could lead to nonlinear optimization problems which could possibly be linearized by approximating the tax penalties with a piece-wise linear function.

We run the model for different carbon credit (or tax) values and investigated the relationships between the carbon emission, the total economic cost $(F)$ of the supply chain network, and the carbon credit (or tax) value. The results are shown in Figure 2.

Figure 2 shows the effect in the carbon emissions (kilograms) and the total cost of the supply chain (Chinese Yuan), given different carbon credit (or tax) values $(\$ / \mathrm{kg})$. The carbon credit price begins relatively low and continues to increase along the horizontal axis. A zero value for carbon credit means neither tax nor trade price has been imposed. After price increases to a certain point, the carbon emissions begin to decrease. The carbon emissions curve presents a piece-wise behavior. When the carbon credit price reaches a certain high level (this value is about $2.5 \$ / \mathrm{kg}$ as shown in Figure 2), the decrease of carbon emissions is negligible and, as result, the carbon emission quantity looks stable. Additionally, the total supply chain network cost, the sum of the economic cost, and the expenses for carbon emissions increase as a linear function of the carbon credit price. These results demonstrate that, for a certain range, carbon credit price incentivizes the reduction of carbon emissions to the environment. However, when price is out of that range, it does not have effect or influence in reducing the carbon emissions.

\subsubsection{Considering the GHGs Emission under Carbon Emis-} sion Cap. The optimization formulation, presented in the previous section, assumes that the carbon emission cap is unlimited over the entire planning horizon. However, in many real situations, firms are often subject to mandatory caps on the amount of carbon they can emit. The carbon emission cap could also vary during the entire planning horizon. We simulate a simplified scenario; that is, the GHG emission amount, at each time period of the planning horizon, does not exceed a certain cap. Accordingly, we update the optimization model with the additional constraint given by the following:

$$
\alpha \sum_{t=1}^{T} \sum_{i=1}^{F} \sum_{j=1}^{S} q_{i j}^{t}+\beta\left(\sum_{t=1}^{T} \sum_{i=1}^{F} \sigma_{i}^{t}+\sum_{t=1}^{T} \sum_{j=1}^{S} \sigma_{j}^{t}\right) \leq \text { cap. }
$$


TABLE 4: Carbon emission factor.

\begin{tabular}{lc}
\hline & Emission factor \\
\hline Inventory $(\mathrm{kg} \mathrm{CO} /$ ton $)$ & 15 \\
Transportation $\left(\mathrm{kg} \mathrm{CO}_{2} /\right.$ ton $\left./ \mathrm{km}\right)$ & 1.24 \\
\hline
\end{tabular}

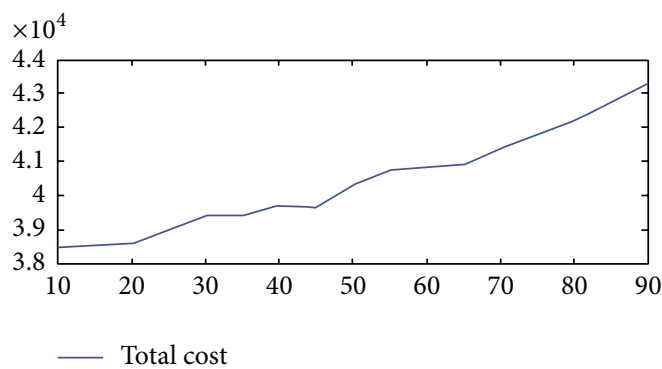

FIgURE 1: Relationship between vehicle capacity and total cost.

The objective function is the same $F_{1}$ defined in Section 3 (see (2)).

The new optimization model has objective function $F_{1}$ (see (2)) and is subject to constraints given by inequalities (4), (5), (6), (7), (8), (9), and (11). The new optimization model corresponds to the $\varepsilon$-constraint method, briefly described at the beginning of Section 4, and can be used to tackle multiobjective optimization problems. We run the proposed model for different carbon emission cap values and investigated the relationships between the total carbon emissions, the total economic cost of the supply chain network, and the carbon emission cap regulation. The results are shown in Figure 3.

Figure 3 depicts the effect of varying the emission cap (kg) in the total economic cost of the supply chain network and total carbon emissions $(\mathrm{kg})$. As expected, when reducing the emission cap, the total cost increases and the carbon emission quantity decreases. At the beginning, when the carbon emission cap increases, the total cost quickly decreases and the amount of carbon emission increases. However, when the carbon emission cap reaches a certain value, the change in the total cost of the supply chain and the carbon emission quantity is insignificant. They appear to be steady. The fact that at a certain range the carbon emission cap can be significantly reduced without affecting significantly the total cost of the supply chain comes as an interesting surprise. In this case, reducing the carbon emission cap from $1200 \mathrm{~kg}$ to $1000 \mathrm{~kg}$ generates an average reduction of $22 \%$ in the amount of carbon emission (the carbon emission changes from $1196 \mathrm{~kg}$ to $933 \mathrm{~kg}$ ). This change represents a $0.41 \%$ increase in the total cost of the supply chain (the total cost changes from $\$ 33,390$ to $\$ 33,530)$. This finding suggests that modifying the carbon emission cap could lead to significant reductions of carbon emission while not significantly compromising the total cost of the supply chain.

\section{Conclusions and Future Work}

This paper focused on the design of a carbon effective biobjective supply chain network. A biobjective optimization model for a real case of a multiperiod one-stage supply

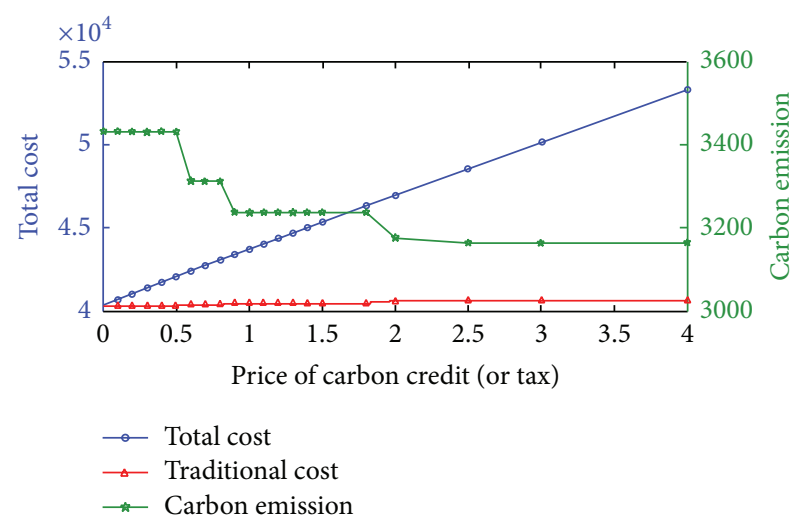

FIGURE 2: Relationship between carbon emissions, total cost, and the carbon credit (or tax).

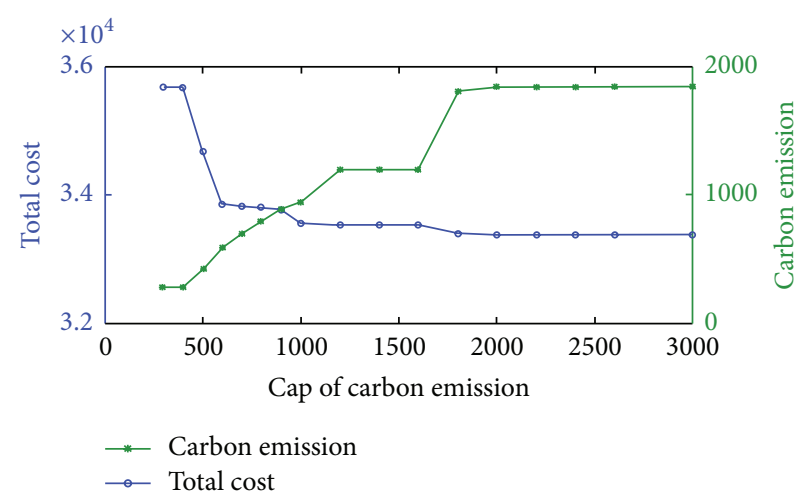

FIGURE 3: The effect of the emission cap in the total cost and carbon emission.

chain distribution network problem was developed. The first objective function deals with minimizing the total cost and the second is aimed at minimizing the carbon emission quantity. The transportation cost between factories and sales points is modelled as a function of the number of vehicles utilized. The vehicles have a predetermined fixed capacity. The forecast of demand is known for the planning horizon and shortage of demand is allowed as long as a minimum service level is satisfied.

Two carbon emission regulatory policies are studied. The carbon credit (tax) regulatory policy is modelled by transforming the biobjective optimization problem into a single objective optimization problem by penalizing the carbon emission objective function. The penalty factor corresponds to the carbon credit or carbon tax. This transformation allows us to solve the problem using the weighted sum method. The second regulatory policy corresponds to the carbon cap. The carbon emission cannot exceed this cap at any time period. An additional constraint is added to the mathematical formulation and the model is transformed into a single objective optimization problem. Lastly, the problem is solved using the $\varepsilon$-constraint method.

The relationships between the total supply chain cost and carbon emission with carbon credit price or carbon tax and emission cap are discussed. Results demonstrated that, 
for a certain range, the carbon credit price incentivizes a reduction of carbon emissions to the environment. On the other hand, modifying the carbon emission cap inside a certain range could lead to significant reductions of carbon emission while not significantly compromising the total cost of the supply chain.

Immediate future research includes the following extensions. Uncertainty in demand is a common scenario which should be incorporated as an extension of the model. Transportation operations could be performed sharing vehicles and routes, which could significantly impact the amount of GHG emissions to the environment. Another straightforward extension is the consideration of multiple products. Lastly, it is important to study other phases of carbon emission based on LCA and supply chain response.

\section{Abbreviations}

\author{
$F: \quad$ Set of factories \\ $S: \quad$ Set of sales points \\ $T$ : $\quad$ Master distribution schedule horizon \\ (planning horizon) \\ $t$ : Distribution scheduling time period (e.g., \\ month, week, and day) from 1 to $T$ \\ $C_{i}$ : Capacity of factory $i, i \in F$ \\ $d_{j}^{t}$ : Demand of sales point $j$ at period of time \\ $t, j \in S$ \\ $h_{i}^{t}$ : Holding cost of factory $i$ at period of time $t$ \\ $\theta_{i}^{t}$ : Setup cost of factory $i$ at period of time $t$ \\ $L_{j}$ : Penalty cost for lost sale at sales point $j$ \\ $\varphi$ : Vehicle capacity \\ CSL: Customer service level \\ $d_{i j}$ : Distance between network node $i$ and $j$ \\ $k_{i j}$ : Vehicle transportation cost from factory $i$ \\ to sales point $j$ : it could be defined as the \\ distance $d_{i j}$ between factory $i$ and sales \\ point $j$ \\ $\alpha$ : Transportation carbon emission factor \\ (per ton/distance) \\ $\beta$ : $\quad$ Greenhouse gas emission factor per \\ weight of product stored in factory and \\ sales point \\ $\Omega$ : Cost of carbon credits in $\$$ per ton of \\ GHG.
}

\section{Decision Variables}

$q_{i j}^{t}$ : Product quantity transported from factory $i$ to sales point $j$ at time $t$

$N_{i j}^{t}$ : Number of vehicles utilized from factory $i$ to sales point $j$ at time $t$

$\sigma_{i}^{t}$ : Stock quantity of factory $i$ at time $t$

$\sigma_{j}^{t}$ : Stock quantity of sales point $j$ at time $t$

$y_{i}^{t}$ : Binary variable which defines whether factory $i$ is active or not at time $t$

$\delta_{j}^{t}$ : Lost sales quantity at sales point $j$ at time $t$.

\section{Competing Interests}

The authors declare that they have no competing interests.

\section{Acknowledgments}

This research project was supported by the Social Science and Humanity Fund of the Ministry of Education of China (Grant no. 14YJA630046) and Zhejiang Provincial Natural Science Foundation of China (Grants nos. LZ14G020001 and LQ14E050001).

\section{References}

[1] C. Labuschagne, A. C. Brent, and R. P. G. van Erck, "Assessing the sustainability performances of industries," Journal of Cleaner Production, vol. 13, no. 4, pp. 373-385, 2005.

[2] A. Chaabane, A. Ramudhin, and M. Paquet, "Design of sustainable supply chains under the emission trading scheme," International Journal of Production Economics, vol. 135, no. 1, pp. 37-49, 2012.

[3] C.-M. Chen, "Evaluating eco-efficiency with data envelopment analysis: an analytical reexamination," Annals of Operations Research, vol. 214, no. 1, pp. 49-71, 2014.

[4] N. Yakovleva, J. Sarkis, and T. Sloan, "Sustainable benchmarking of supply chains: the case of the food industry," International Journal of Production Research, vol. 50, no. 5, pp. 1297-1317, 2012.

[5] J. Q. F. Neto, J. M. Bloemhof-Ruwaard, J. A. E. E. van Nunen, and E. van Heck, "Designing and evaluating sustainable logistics networks," International Journal of Production Economics, vol. 111, no. 2, pp. 195-208, 2008.

[6] R. Dekker, J. Bloemhof, and I. Mallidis, “Operations Research for green logistics-an overview of aspects, issues, contributions and challenges," European Journal of Operational Research, vol. 219, no. 3, pp. 671-679, 2012.

[7] K.-H. Lai and C. W. Y. Wong, "Green logistics management and performance: some empirical evidence from Chinese manufacturing exporters," Omega, vol. 40, no. 3, pp. 267-282, 2012.

[8] S. Benjaafar, Y. Li, and M. Daskin, "Carbon footprint and the management of supply chains: insights from simple models," IEEE Transactions on Automation Science and Engineering, vol. 10, no. 1, pp. 99-116, 2013.

[9] M. T. Melo, S. Nickel, and F. Saldanha-Da-Gama, "Facility location and supply chain management-a review," European Journal of Operational Research, vol. 196, no. 2, pp. 401-412, 2009.

[10] W. Klibi, A. Martel, and A. Guitouni, "The design of robust value-creating supply chain networks: a critical review," European Journal of Operational Research, vol. 203, no. 2, pp. 283293, 2010.

[11] R. Z. Farahani, S. Rezapour, T. Drezner, and S. Fallah, "Competitive supply chain network design: an overview of classifications, models, solution techniques and applications," Omega, vol. 45, pp. 92-118, 2014.

[12] G. Nagy and S. Salhi, "Location-routing: issues, models and methods," European Journal of Operational Research, vol. 177, no. 2, pp. 649-672, 2006.

[13] A. Amiri, "Designing a distribution network in a supply chain system: formulation and efficient solution procedure," European Journal of Operational Research, vol. 171, no. 2, pp. 567-576, 2006. 
[14] A. Azaron, K. N. Brown, S. A. Tarim, and M. Modarres, "A multi-objective stochastic programming approach for supply chain design considering risk," International Journal of Production Economics, vol. 116, no. 1, pp. 129-138, 2008.

[15] R. B. Franca, E. C. Jones, C. N. Richards, and J. P. Carlson, "Multi-objective stochastic supply chain modeling to evaluate tradeoffs between profit and quality," International Journal of Production Economics, vol. 127, no. 2, pp. 292-299, 2010.

[16] C. Speier, J. M. Whipple, D. J. Closs, and M. D. Voss, "Global supply chain design considerations: mitigating product safety and security risks," Journal of Operations Management, vol. 29, no. 7-8, pp. 721-736, 2011.

[17] M. S. Pishvaee, J. Razmi, and S. A. Torabi, "Robust possibilistic programming for socially responsible supply chain network design: a new approach," Fuzzy Sets and Systems, vol. 206, pp. 1-20, 2012.

[18] H. Sadjady and H. Davoudpour, "Two-echelon, multicommodity supply chain network design with mode selection, lead-times and inventory costs," Computers \& Operations Research, vol. 39, no. 7, pp. 1345-1354, 2012.

[19] Y. Cardona-Valdés, A. Álvarez, and D. Ozdemir, "A bi-objective supply chain design problem with uncertainty", Transportation Research Part C: Emerging Technologies, vol. 19, no. 5, pp. 821832, 2011.

[20] A. Baghalian, S. Rezapour, and R. Z. Farahani, "Robust supply chain network design with service level against disruptions and demand uncertainties: a real-life case," European Journal of Operational Research, vol. 227, no. 1, pp. 199-215, 2013.

[21] A. Ahmadi Javid and N. Azad, "Incorporating location, routing and inventory decisions in supply chain network design," Transportation Research Part E: Logistics and Transportation Review, vol. 46, no. 5, pp. 582-597, 2010.

[22] S. R. Cardoso, A. P. F. D. Barbosa-Póvoa, and S. Relvas, "Design and planning of supply chains with integration of reverse logistics activities under demand uncertainty," European Journal of Operational Research, vol. 226, no. 3, pp. 436-451, 2013.

[23] M. Esmaeilikia, B. Fahimnia, J. Sarkis, K. Govindan, A. Kumar, and J. Mo, "A tactical supply chain planning model with multiple flexibility options: an empirical evaluation," Annals of Operations Research, 2014.

[24] F. Pan and R. Nagi, "Multi-echelon supply chain network design in agile manufacturing," Omega, vol. 41, no. 6, pp. 969-983, 2013.

[25] T. Abdallah, A. Farhat, A. Diabat, and S. Kennedy, "Green supply chains with carbon trading and environmental sourcing: formulation and life cycle assessment," Applied Mathematical Modelling, vol. 36, no. 9, pp. 4271-4285, 2012.

[26] S. Seuring and M. Müller, "From a literature review to a conceptual framework for sustainable supply chain management," Journal of Cleaner Production, vol. 16, no. 15, pp. 1699-1710, 2008.

[27] E. Hassini, C. Surti, and C. Searcy, "A literature review and a case study of sustainable supply chains with a focus on metrics," International Journal of Production Economics, vol. 140, no. 1, pp. 69-82, 2012.

[28] A. Sbihi and R. W. Eglese, "Combinatorial optimization and green logistics," Annals of Operations Research, vol. 175, no. 1, pp. 159-175, 2010.

[29] M. Brandenburg, K. Govindan, J. Sarkis, and S. Seuring, "Quantitative models for sustainable supply chain management: developments and directions," European Journal of Operational Research, vol. 233, no. 2, pp. 299-312, 2014.
[30] B. Ageron, A. Gunasekaran, and A. Spalanzani, "Sustainable supply management: an empirical study," International Journal of Production Economics, vol. 140, no. 1, pp. 168-182, 2012.

[31] Y. J. Chen and J.-B. Sheu, "Environmental-regulation pricing strategies for green supply chain management," Transportation Research Part E: Logistics and Transportation Review, vol. 45, no. 5, pp. 667-677, 2009.

[32] B. Sundarakani, R. De Souza, M. Goh, S. M. Wagner, and S. Manikandan, "Modeling carbon footprints across the supply chain," International Journal of Production Economics, vol. 128, no. 1, pp. 43-50, 2010.

[33] H. Krikke, "Impact of closed-loop network configurations on carbon footprints: a case study in copiers," Resources, Conservation and Recycling, vol. 55, no. 12, pp. 1196-1205, 2011.

[34] F. Wang, X. Lai, and N. Shi, "A multi-objective optimization for green supply chain network design," Decision Support Systems, vol. 51, no. 2, pp. 262-269, 2011.

[35] S. Elhedhli and R. Merrick, "Green supply chain network design to reduce carbon emissions," Transportation Research Part D: Transport and Environment, vol. 17, no. 5, pp. 370-379, 2012.

[36] R. Jamshidi, S. M. T. F. Ghomi, and B. Karimi, "Multi-objective green supply chain optimization with a new hybrid memetic algorithm using the Taguchi method," Scientia Iranica, vol. 19, no. 6, pp. 1876-1886, 2012.

[37] A. Ramudhin, A. Chaabane, and M. Paquet, "Carbon market sensitive sustainable supply chain network design," International Journal of Management Science and Engineering Management, vol. 5, no. 1, pp. 30-38, 2010.

[38] S. Du, F. Ma, Z. Fu, L. Zhu, and J. Zhang, "Game-theoretic analysis for an emission-dependent supply chain in a 'cap-andtrade' system," Annals of Operations Research, vol. 228, no. 1, pp. 135-149, 2011.

[39] S. Du, L. Zhu, L. Liang, and F. Ma, "Emission-dependent supply chain and environment-policy-making in the 'cap-and-trade' system," Energy Policy, vol. 57, pp. 61-67, 2013.

[40] C. Dong, B. Shen, P.-S. Chow, L. Yang, and C. T. Ng, "Sustainability investment under cap-and-trade regulation," Annals of Operations Research, vol. 240, no. 2, pp. 509-531, 2016.

[41] S. Seuring, "A review of modeling approaches for sustainable supply chain management," Decision Support Systems, vol. 54, no. 4, pp. 1513-1520, 2013.

[42] D. Konur and B. Schaefer, "Integrated inventory control and transportation decisions under carbon emissions regulations: LTL vs. TL carriers," Transportation Research Part E: Logistics and Transportation Review, vol. 68, pp. 14-38, 2014.

[43] J. M. C. Martí, J.-S. Tancrez, and R. W. Seifert, "Carbon footprint and responsiveness trade-offs in supply chain network design," International Journal of Production Economics, vol. 166, pp. 129142, 2015.

[44] R. Hammami, I. Nouira, and Y. Frein, "Carbon emissions in a multi-echelon production-inventory model with lead time constraints," International Journal of Production Economics, vol. 164, pp. 292-307, 2015.

[45] IPCC, Guidelines for National Greenhouse Gas Inventories, 2006.

[46] EPA, "US transportation sector greenhouse gas emissions: 1990-2011," Tech. Rep. EPA-420-F-13-033a, US Environmental Protection Agency, Office of Transportation and Air Quality, 2013. 


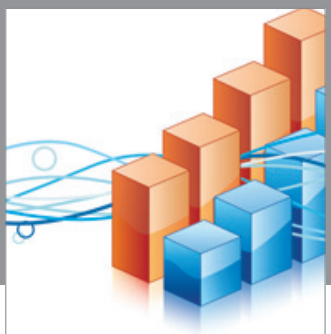

Advances in

Operations Research

vatem alat4

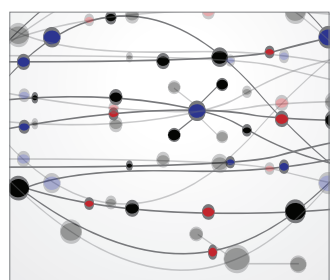

\section{The Scientific} World Journal
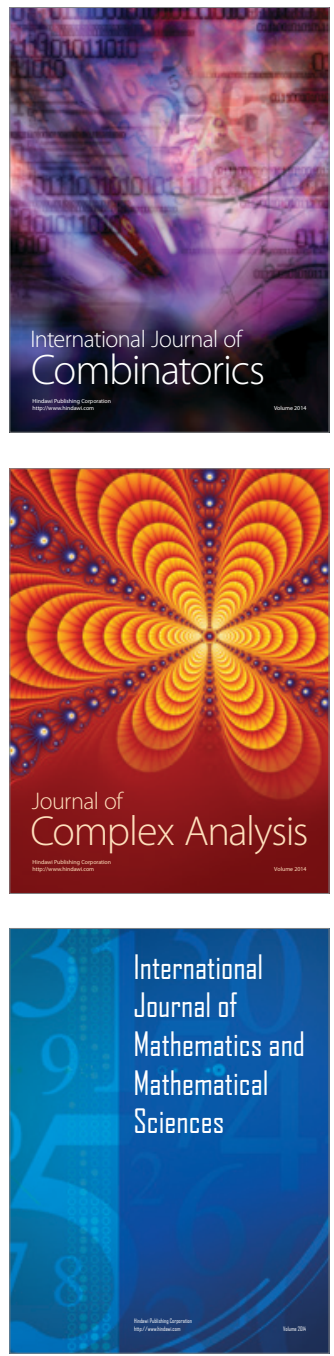
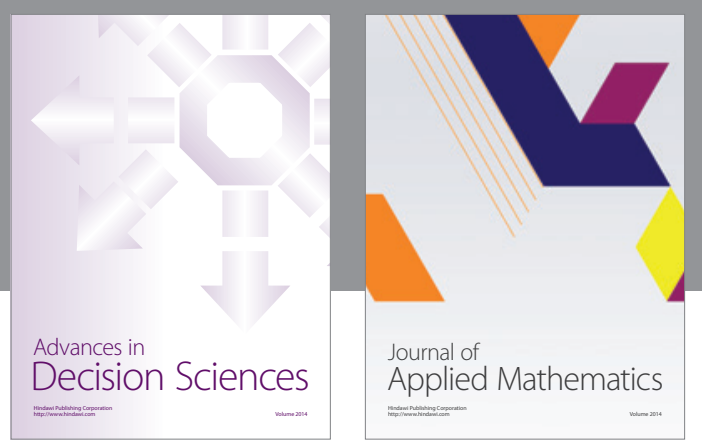

Algebra

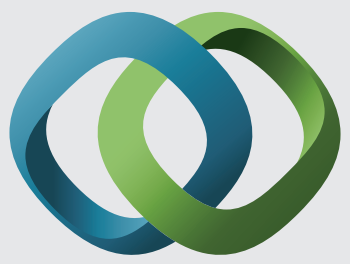

\section{Hindawi}

Submit your manuscripts at

http://www.hindawi.com
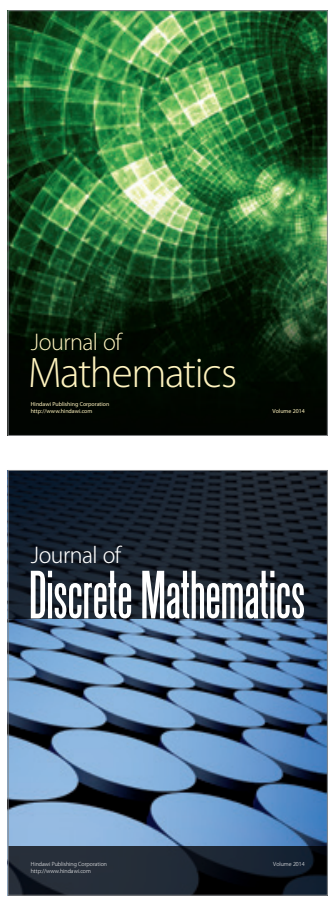

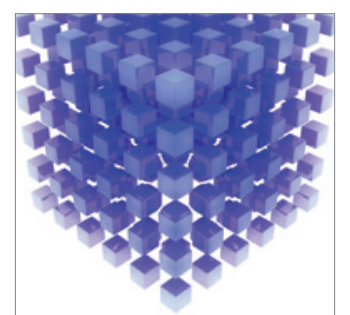

Mathematical Problems in Engineering
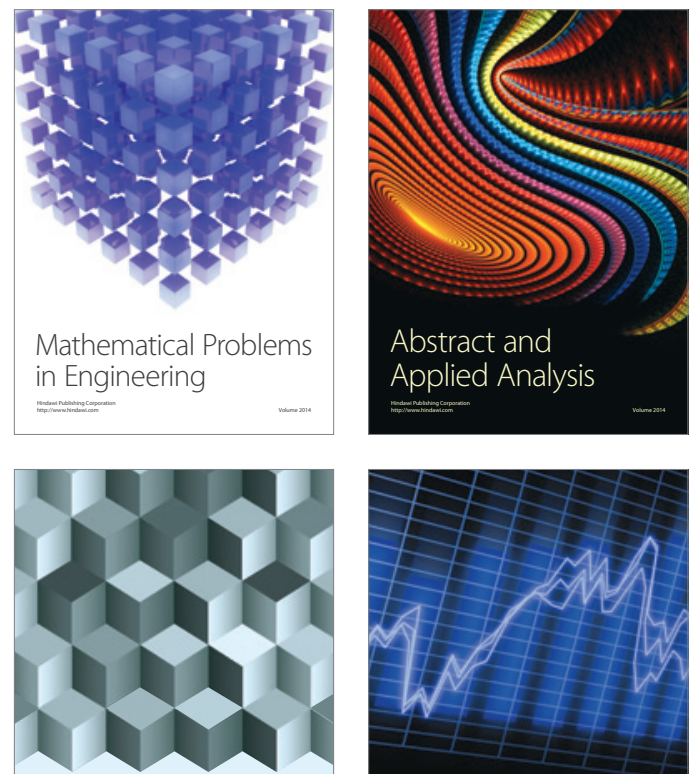

Journal of

Function Spaces

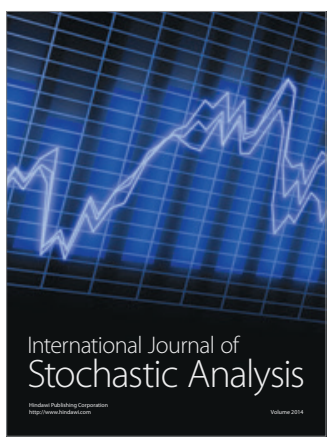

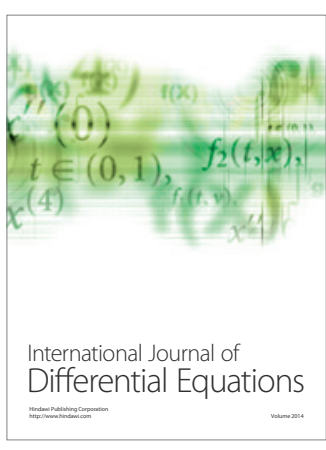
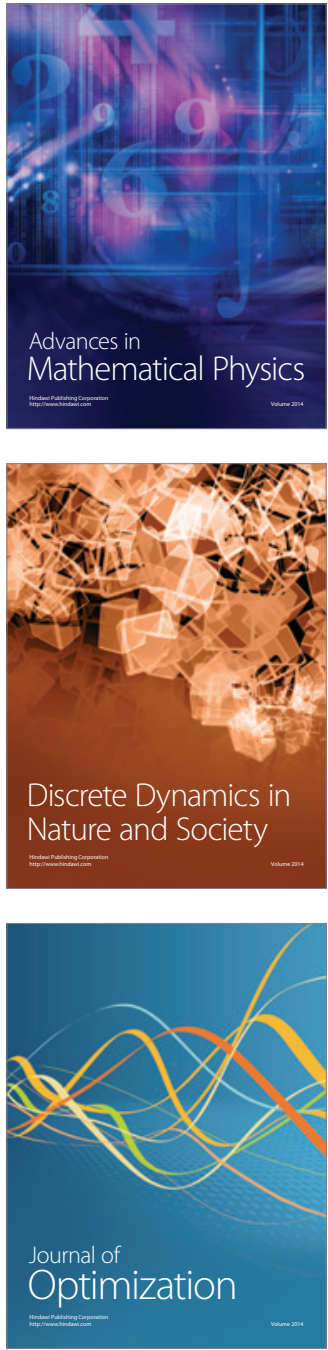